\title{
It Requires a Community to Raise a Deaf Adult: A Comparative Study
}

\author{
Tracy Knight ${ }^{*}$, Sean Hauschildt ${ }^{2}$, Beverly Buchanan², Ashley Greene ${ }^{2}$, M. Diane Clark ${ }^{2}$ \\ ${ }^{1}$ Sam Houston State University, Huntsville, USA \\ ${ }^{2}$ Lamar University, Beaumont, USA \\ Email: *trk033@shsu.edu
}

How to cite this paper: Knight, T., Hauschildt, S., Buchanan, B., Greene, A., \& Clark, M. D. (2021). It Requires a Community to Raise a Deaf Adult: A Comparative Study. Open Journal of Social Sciences, 9, 77-95. https://doi.org/10.4236/jss.2021.93006

Received: December 19, 2020

Accepted: March 9, 2021

Published: March 12, 2021

Copyright $\odot 2021$ by author(s) and Scientific Research Publishing Inc. This work is licensed under the Creative Commons Attribution International License (CC BY 4.0).

http://creativecommons.org/licenses/by/4.0/

(c) (i) Open Access

\begin{abstract}
It has often been said, "It takes a village to raise a child"; likewise for deaf children born into hearing families, this village model provides the support necessary for optimal developmental outcomes for the child. Here a mixed method design was used to understand the outcomes for deaf adults who grew up a mid-size community with fragmented services in order to better understand what worked and what had not worked for these individuals. Results from a survey and follow up interviews identified two groups of individuals, those who stayed in the community having access only to the local resources and those who left the community finding more resources. In general, those who stayed described themselves as hard of hearing and used a mixture of sign and spoken language while those who left identified as Deaf and reported finding a Deaf community that provided them role models, aspirational capital, and a Deaf identity. Results are discussed using the frame of integrating support for families, effective schooling, and transition services. Recommendations are made to support the creation of such villages for deaf children in areas that may not have sufficient resources.
\end{abstract}

\section{Keywords}

Aspirational Capital, Deaf and Hard of Hearing, Deaf Community, Resources

\section{Introduction}

Several deaf ${ }^{1}$ university faculty went to a local Deaf Night Out event where their

${ }^{1}$ The authors wish to respect varying identities and preferences. The term "deaf" will be used in this manuscript in an all-inclusive manner to include all varying identities related to the term "deaf" as recommended by the National Deaf Center. Deaf will be used to refer to specific culturally deaf components such as Deaf culture and Deaf identity. 
students and the local deaf community met to provide opportunities for language learning. During the event, the faculty noticed that many deaf people who resided in the area were not employed, did not have degrees, and did not appear to have the support necessary to obtain a higher education degree. Additional interactions identified weaknesses, particularly in empowerment, identity, and language proficiency, which led to questions about the characteristics of the community. In time, it was learned that there were many challenges that the local deaf community faced, which appeared to be partly due to the location of the city in this study. This project emerged from curiosity about local available services and more long term outcomes for the deaf community.

\subsection{History of the Local Deaf Community}

To better understand this community, two adult Children of Deaf Adults (CODAs) were asked to share the history of the local deaf community, dating back to the 1960s prior to the implementation of the Americans with Disabilities Act (ADA). Both individuals grew up in the area in deaf families and have first-hand experience of the deaf community dating back several decades. Their knowledge and input regarding the history of the community was valuable to understand the ongoing context. Due to the impact that ADA had on disabled communities, these experiences, while an essential part of history, likely will not reflect current experiences. However, to truly have an impact and make changes, we must look back in history and see what has and has not been effective.

Prior to ADA, there were limited resources available for deaf individuals to communicate, such as TTYs, VideoPhones, or community interpreters. During this time, there were no Interpreter Training Programs (ITP) locally, and thus community interpreters were scarce. The lack of availability of interpreters in the community led to lower job opportunities, reduced access in educational settings, and the need for these CODA children to interpret in educational, legal, and/or medical settings. An example can be seen when one of the CODA's told a story of her sister standing by the TV interpreting the news when Former President John F. Kennedy was assassinated. Her sister at the time was too young to understand the vocabulary, (i.e., "assassinate") so the message that was interpreted to her parents came from the viewpoint of a child. Her parents did not understand what was happening, only that many people on their TV screen were crying and something happened to JFK.

During the 1950's and 1960's, the local deaf community started their own Deaf Club at a deaf person's home. Due to the lack of funding, the club did not have a permanent location, rather members would rent rooms at hotels, use space at people's houses, and temporarily rent space at different venues in the area. The Deaf Club provided the local deaf community with opportunities to socialize, share information, and network; these opportunities were crucial for stimulation and access to language. In the early 2000's, there were no remaining members in the community interested in running the club, leading to the club closing permanently. Next, the description of services for the deaf community in 
a small town is elaborated below.

It was shared that many in the community who attended the local schools often ended up on Social Security Income (SSI) or Social Security Disability Income (SSDI). This lack of employment may be attributed to the lack of deaf adult mentorship in schools for deaf students, the poor qualifications of the local educational interpreters, and the limited availability of jobs in the community. During various interactions in the community through the past year, the local community members shared with faculty that there no longer was a vocational rehabilitation (VR) office in the area. However, after further investigation, it was found that the local office had been merged into another office in a larger city approximately 90 miles away and that services were still available. It appears that the community is either unaware or unable to capitalize on these services. The members of the Deaf community in this region who need the services most are typically recipients of social security income (SSI/SSDI) and do not have access to the internet or computers.

The removal of VR services and the lack of a Deaf Club also led to poor awareness regarding Deaf culture in the community. A recent incident cast a spotlight on the need for services in this community. A deaf adult wanted to seek services in the form of access to a VideoPhone and went to the local university to a building which formerly housed a Deaf Studies and Deaf Education department. In the confusion between the current department in that building and broken communication between the hearing individuals and deaf adult, police were called to arrest the deaf individual. One of the CODAs from this interview went to the building to interfere and explain to the police officer that this individual was not here to cause trouble, rather they were requesting services and had limited language skills to communicate those needs. This situation thrust the need for a resource specialist back in the community, more advocacy services, job training, and community enrichment.

\subsection{Characteristics of the National Deaf Community}

To understand what is happening at the local level, we must step back and look at what is happening in the Deaf community on a nation-wide level. These local issues are not uncommon for deaf people as a recent report from the National Deaf Center found that in 2017, there was a $22.5 \%$ gap in employment between deaf and hearing individuals (NDC; Employment Report Shows Strong Labor Market Passing by Deaf Americans) and that their rates of employment have not increased since 2008. In addition, $42.9 \%$ of deaf people have opted out of the labor forces, a rate that is more than twice that of hearing individuals. When asked why they opt out, deaf people report that they tend to only be offered low-level jobs that lack advancement opportunities and that they get "burned out" confronting all of the barriers and bias in a hearing workplace.

Wheeler-Scruggs (2003) identified three categories of risk factors for deaf people, including personal attributes, social conditions, and service delivery. As 
also noted by the NDC report, gender, ethnicity and secondary disabilities are some of those personal attributes also noted in Wheler-Scruggs as risk factors for lower levels of employment. In terms of social conditions, lack of communication with family members, a lack of role models, and lower social-economic status increase the likelihood that deaf individuals will have difficulty with both employment and life satisfaction. Moreover, many skilled jobs, such as printing and shoe repair, have been replaced by technology. In terms of service delivery, a lack of interpreters and a lack of access to services make finding and holding a job difficult for deaf individuals. Finally, as noted in the NDC reports as well as Eraser et al. (2019), and Wheeler-Scruggs (2003), there are negative employer attitudes that impact the quality of life for deaf individuals and increase the likelihood that they will decide to opt out of the labor force.

Additionally, as noted in Eraser et al. (2019) many employers are hesitant to hire a deaf person as they are concerned with the cost related to the American with Disabilities Act (ADA, 1990) that requires that employers provide reasonable accommodations. Historically, one rationale offered for not hiring a deaf person was that they were unable to use the phone; however, with the current technologies deaf people can text, use video relay interpreters, and workplaces are able to install VideoPhones for their deaf employees that are free to deaf users (Punch, 2016). These newer services still may not be able to overcome the negative attitudes of many employers. Regardless, Eraser et al. (2019) note that employers are eligible for tax credits when providing accommodations for deaf employees, which may not be known to employers.

Another major issue is communication and language for deaf individuals. As 95\% of deaf children are born to hearing parents (Mitchell \& Karchmer, 2004), a large majority of deaf infants are fitted with hearing technologies (i.e., hearing aids and/or cochlear implants) with the goal of using spoken language. However, many deaf children who received cochlear implants do not develop effective spoken language and show delays in educational outcomes (Mukari et al., 2007). This lack of full access to spoken language by deaf children frequently leads to serious language delays (Humphries et al., 2016) with many deaf individuals leaving high school with reading levels that are extremely low; frequently cited as the 4th grade level (Easterbrooks \& Beal-Alarez, 2012). Given these difficulties, frequently deaf adults switch to sign language and integrate into Deaf culture (Cue, 2020). Therefore, hearing people use spoken language that is accessed through the auditory sensory system while many deaf people use sign language that comes in through the visual sensory system (Greene-Woods et al., 2021), establishing two distinct cultures.

These cultural and linguistic differences then impact job success (Greene-Woods et al., 2021). People are frequently surprised that deaf people have a tendency to be loud and violate Grice's maxims (Surian et al., 2010), which can lead to the cultural differences which are presented in Table 1 and adapted from GreeneWoods et al. (2021). Therefore, deaf individuals who sign and lack full access to 
Table 1. American deaf culture versus American hearing culture.

\begin{tabular}{l} 
American Deaf Culture \\
\hline Farewell, prolonged farewells are considered \\
polite. Short and abrupt departures are \\
considered rude. \\
Introductions, when introducing a person, it is \\
considered acceptable and polite to provide \\
background details and share personal stories.
\end{tabular}

Eye contact, direct eye contact is considered American Hearing Culture

Farewell, short farewells are typical in hearing culture. Long farewells are not common.

Introduction, when introducing a person, information is often limited to the person's name and relation to the person doing the introduction.

Eye contact, direct eye contact is acceptable for polite. Lack of eye contact is considered rude and short periods of time, but extensive eye contact is indicates a lack of listening.

considered rude or appears as if one is staring.

Pointing, the use of pointing in ASL replaces pronouns. Pointing is also considered acceptable when discussing objects or people in the room.

Food in mouth, communicating with food in one's mouth is not considered rude.

Money, discussion of money and salaries are considered normal.

Pointing, the use of pointing in hearing culture is considered rude, especially when pointing to people.

Food in mouth, communicating with food in one's mouth is considered rude.

Money, discussion of money, salaries, and other financial information is considered private and is generally not shared with others.

Punctuality, punctuality is not typically expected. In fact, there is often a saying, Deaf Standard Time, to explain tardiness.

Punctuality, punctuality is expected.

Personal questions, Deaf culture tends to "overshare" as a means of getting information to understand the world around them and thus personal questions such as "how much weight have you gained", "why did you get a divorce?" are considered normal.

Personal questions, Hearing culture involves keeping most information private. Questions about one's personal life (e.g. marriage, divorce, weight gain) are considered rude.

Attention getting, Deaf culture relies on the visual modality, and thus attention getting behaviors cater to visual or kinetic sensory systems. Appropriate behaviors include tapping on shoulders, waving arms, stomping on the floor, banging on surfaces that create vibrations, Attention, To get attention, hearing people use vocal methods such as calling one's name. They often do not incorporate touch to get attention and avoid the use of touch for that purpose. and short loud verbal noises.

spoken language do not learn Grice's maxims in their home contexts as frequently parents are unable to communicate these subtle cultural values (Cue, 2020). These cultural differences lead to conflicts in the workplace, especially if the supervisor is hearing and the employee is deaf.

Given these differences, it is challenging for hearing supervisors to make accommodations for their deaf workers because they are not always familiar with which accommodations are needed for deaf individuals because not all have the same needs. Particularly, communication preferences vary from American Sign Language (ASL), to Signed English, and spoken language; additionally, some deaf individuals may not have strong reading and writing skills for effective communication with their hearing supervisors (Dammeyer et al., 2019; Stokar \& 
Orwat, 2018). The interpersonal communication between hearing supervisors and deaf workers are not always effective but with more shared awareness, friction can be reduced between deaf employees and hearing supervisors (Stokar \& Orwat, 2018). However, these interactions are not necessarily always negative, as there are some positive outcomes. For instance, if there is a language barrier for workers with different language backgrounds then they will figure out how to communicate with each other nonverbally via gestures. This approach may help to develop friendships between workers, which will highly likely lead to a successful productive work environment (Stokar \& Orwat, 2018).

The research question for this study was a general one: What are the needs of deaf members of the local community? The study was designed prior to COVID occurring so had to be modified to include the use of a video platform, reducing the amount of interviews that were possible. Regardless, data was collected from those who grew up in the area and were willing to share their experiences with us using a mixed method design that included first a survey and then a qualitative semi-structured interview.

\section{Methodology}

\subsection{Procedure}

\subsubsection{Survey}

Upon approval from the university's IRB, an electronic survey was created and distributed via Qualtrics. Participants were recruited using the snowball method (Naderifar et al., 2017), social media, and personal correspondence. Each participant read and signed the informed consent, which was presented in both ASL and English text. After signing the form in a Qualtrics survey, participants were then allowed to complete the survey. The survey consisted of 20 questions, with six of those questions focusing on demographics. The remaining 14 questions were closed-ended questions. As the presence of a mentor has been shown to have a significant impact on deaf adults (Greene-Woods et al., 2021), several questions asked about the presence of a signing mentor during K-12 years and in the workplace. To learn about the quality of education, questions were asked about education placement, presence of signing teachers, or availability of interpreters. The remaining questions focused on the participants' employment history and experiences in the workplace. To maintain full accessibility to each participant, each survey question was provided using both an ASL video and English transcription. The goal of the survey was to collect information on current local deaf residents residing in a town of approximately 120,000 which is located 90 miles from the nearest large city. It focused on how available services impacted their ability to navigate their lives in regard to their academic, professional, and personal day-to-day lives.

\subsubsection{Interviews}

The COVID-19 pandemic changed the original aim of interviewing deaf individuals in a focus group format during a Deaf event to individual interviews, 
mostly through video. Six deaf individuals gave consent to participate in interviews, which were conducted in ASL and videotaped. A semi-structured interview protocol was used for each interview, with the same list of predetermined questions to help guide the interview and reduce interviewer bias (Kelley et al., 2003). The interviews were then translated from ASL into English for coding purposes.

\subsection{Participants}

\subsubsection{Survey Participants}

Individuals who met the following criteria were invited to participate in the survey: 1) identified as D/deaf, hard of hearing, hearing impaired, or late-deafened; 2) were over 18 years of age; and 3) grew up in or near the area specified in this study. The survey yielded 20 participants who responded to six questions regarding gender, age, communication preferences, education, and hearing identity, (see Table 2 for their backgrounds). Overall, there were more white women than men or people of color. Most of the participants were middle aged. Education varied from below high school to a doctorate. Most labeled themselves as deaf. When asked about hearing technologies, these participants reported the use of a cochlear implant $(n=1)$, previous use of a cochlear implant $(n=2)$, the use of hearing aids $(n=6)$, and the previous use of hearing aids $(n=7)$. The remaining participants reported that they have not and do not wear any type of hearing technology.

\subsubsection{Interview Participants}

The interview sample consisted of six participants: four men and two women.

Table 2. Demographics of survey participants $(\mathrm{N}=20)$.

\begin{tabular}{|c|c|c|c|}
\hline \multicolumn{2}{|l|}{ Gender } & \multicolumn{2}{|l|}{ Highest Level of Education Completed } \\
\hline Female & 14 & Below high school & 1 \\
\hline Male & 5 & High school degree or GED & 2 \\
\hline \multicolumn{2}{|l|}{ Age } & Some undergraduate college credits, no degree & 1 \\
\hline Under 35 & 1 & Certificate & 2 \\
\hline Between 36 to 50 & 10 & Associate's degree & 3 \\
\hline Between 51 to 75 & 9 & Bachelor's degree & 2 \\
\hline \multicolumn{2}{|c|}{ Communication Preference } & Some graduate college credit, no degree & 1 \\
\hline ASL & 11 & Master's degree & 4 \\
\hline Spoken English & 1 & Doctorate degree & 1 \\
\hline Mixture of modalities & 8 & Hearing Identity & \\
\hline \multicolumn{2}{|l|}{ Ethnicity } & D/deaf & 17 \\
\hline White or Caucasian & 15 & Late deafened & 2 \\
\hline Mixed ethnicity & 1 & Hard of hearing & 1 \\
\hline Prefer not to report & 4 & & \\
\hline
\end{tabular}


The participants were given pseudonyms that were chosen in alphabetic order: Alvin, Bobby, Christopher, Daniel, Elizabeth, and Fawn. Two of the male participants identified themselves using three terms: "I am deaf, but in [specific] ear, I am hard of hearing. With my hearing aids, I can hear." Christopher reported that he used to identify himself as "hard of hearing" but attending a Deaf-centric University led to a shift in identity, where he now identifies as "capital D Deaf." Alvin identified as Black, while Bobby and Christopher identified as White. When asked to describe his identity, Daniel reported "I am hard of hearing, I can speak well." Elizabeth and Fawn are women who both identify as Deaf. The educational backgrounds of the participants ranged from high school diploma to doctoral degree. The ages for the interview participants were all within the 40 to 60 years age range.

\subsection{Data Analytical Plan}

\subsubsection{Survey Data}

The survey data was exported from Qualtrics into SPSS. The authors analyzed the SPSS data using descriptive statistics and frequency counts. All questions were provided in close-ended format.

\subsubsection{Interviews}

Content analysis was used to analyze the English transcripts of each interview. Two research team members identified five themes from both the survey and the interview transcriptions. The coding process was done individually, then together to determine an interrater reliability of $91 \%$. The remaining themes that were not agreed upon were discussed until a consensus of $100 \%$ was reached.

\section{Results}

\subsection{Survey Data}

Participants were asked to report their K-12 experience to determine what impact these formative years had on their life as an adult. In response to the question about having a mentor during K-12, the majority reported yes $(\mathrm{n}=14)$. When asked if they currently have a mentor in the workplace, the majority reported no $(\mathrm{n}=11)$. In regard to the type of classroom settings each participant experienced, the majority reported that they were in both general education classes and deaf education classes $(n=9)$. The remaining were split between full placement in general education classes $(n=5)$ and full placement in deaf education classes $(n=5)$ with one missing dataset. However, the majority of participants reported that they had teachers who signed $(n=16)$, indicating that those who were fully mainstreamed may have received some type of services from a deaf education teacher. The majority of participants reported that they had interpreters in school $(\mathrm{n}=13)$.

Participants were asked eight yes or no questions and three questions about school placement, how long they had been at their job, and how long they had been in their current field. Results are reported in Table 3 for the first eight 
Table 3. Survey results $(\mathrm{N}=20)$.

\begin{tabular}{lcc}
\hline \multicolumn{1}{c}{ Question } & Yes & No \\
\hline Did you have a mentor during your K-12 years? & 14 & 8 \\
Do you currently have a mentor in the workplace? & 9 & 11 \\
Did you have a teacher who signed? & 16 & 4 \\
Did you have an interpreter in school? & 13 & 7 \\
Are you currently employed? & 12 & 8 \\
Do you hold certificates related to your current job? & 7 & 13 \\
Do you want a higher position in your field? & 10 & 9 \\
\hline
\end{tabular}

questions. In terms of employment, with more than half reporting they were currently employed $(\mathrm{n}=12)$; however, a large number also reported they were not currently employed $(\mathrm{n}=8)$. To see if qualifications were a barrier to employment opportunities, participants were asked if they held certificates related to their current jobs, with the majority reporting no (see Table 3). Participants who were currently employed at the time of the study reported that they have been at the same job for less than a year $(\mathrm{n}=6), 1-5$ years $(\mathrm{n}=6), 11-15$ years $(\mathrm{n}=1)$, and more than 16 years $(\mathrm{n}=2)$. When asked how many years they have been working in their current field, the participants reported less than one year $(\mathrm{n}=4), 1-5$ years $(\mathrm{n}=4), 6-10$ years $(\mathrm{n}=2)$, and more than 16 years $(\mathrm{n}=6)$. Half of the participants $(n=10)$ reported that they did want a higher position in their field. The participants who reported they did not want a higher position at work, gave the following reasons, including; "prejudice against deaf people", "people at work do not accept me", and "there is a barrier due to my cerebral palsy [in terms of] access to the job and [additional] education".

As can be seen in these results, there appears to be wide variation in the results to this survey. Educational levels ranged from not completing high school to obtaining a doctoral degree. Having mentors was split with about one half having them in school and the other not having a mentor in school. Similarity, half of the participants wanted higher promotions at work while the other half did not and were no longer actively seeking employment. To better understand these results, more detailed interviews were conducted.

\subsection{Interviews}

The codes that emerged from the analysis of the interviews were: communication, support, empowerment, education, and identity. Interestingly, in further analyzing these themes it became apparent that participants fell into two separate groups; those who had stayed in the area and those who had left the area. Participants Fawn, Daniel, Alvin, and Bobby remained in the area while Christopher and Elizabeth left the area as teenagers. Therefore, the results will be presented by theme across each of these two groups.

\subsubsection{Communication}

Communication differed between those who stayed and those who left the area. 
Those who remained reported that their parents did not sign and that they used spoken language with their families. For example Bobby stated, "My family did not sign and they communicated with me through spoken language. I went to the local University's Speech Clinic and learned to talk." In contrast the group who later left the area had parents who could sign, even if the signing was not fluent ASL. Christopher responded:

All members of my family are hearing. My parents could sign. At first, my father signed then the role switched to my mother when I was growing up. My father went away often as he was in the Air Force and my mother's sign is more in English order. She tried to learn ASL but it is difficult for her. My sister also knows sign language.

Others also mentioned that their families communicated in some form of sign with them, either through fingerspelling or Signing Exact English (SEE). Christopher stated that it was important for him to finally go to the state School for the Deaf to meet deaf role models and that "(this school) had the biggest impact on my life as a deaf person". He went on to state that he no longer communicates with his father as he did not "make an effort to communicate directly" with him.

Given these comments, you can see the differences between the two groups of participants. Those who stayed in the area tended to use spoken language even though "it was not easy", especially when they interacted with hearing people. This limited their ability to engage in academic discourse and they stayed in school here in the area, which will be expanded on under the theme of education. In contrast, those who left had more interactions with their hearing families in sign language, providing them more access to ongoing events in their daily lives. Notice that one participant explicitly explained the importance of going to the state School for the Deaf where he had Deaf role models and access to academic contact as well as social language with peers. These comments lead us to the next theme of support.

\subsubsection{Support}

Support again was different between the two groups. In the interviews, we saw different types of support: support from families, mentors, the education system, and from VR counselors. Those who remained in the area noted limited to no support from their parents, especially in terms of finding employment. When asked about the type of support they received from their families to achieve their professional goals, Fawn stated that she "kind of has a relationship with her family" and that she "received no support from her family".

As a person who left the area, Elizabeth's experience differed in that she reported her mother's "support and high expectations" led to her ability to pursue higher education and secure employment. Elizabeth went on to state "from my perspective, I think parents play a big role in deaf children's lives. Without that support, there may be more limitations. My mother was the key to my success." 
Having access to mentors has been shown to have a significant influence on individuals with disabilities' ability to navigate different expectations. The participants were asked whether they had access to a mentor, either during their time in school or in their place of employment. Again, the two groups differed in their responses with those who stayed in the area reporting they did not have a mentor in either place. Alvin reported that he "did not have a mentor. In school, I was always with my teacher or special education professionals. At work, I work independently without any mentors. If I need an interpreter, I ask for one." Similarly, Daniel and Fawn reported they were not given access to a mentor in the workplace. Bobby's limited understanding of language prevented him from answering the question as he did not understand the meaning of the word mentor.

In contrast, the two who left the area had higher levels of support. Elizabeth again referred to her mother as her primary mentor during her time in school and reported that she "has access to a hearing mentor who is a wonderful person and supports me with whatever I need" in the workplace. Christopher mentioned that he had a mentor who helped with social skills in the sixth grade. Looking back, he said "I learned more from my older deaf peers on the bus as I observed them on a daily basis. They cursed, talked about other deaf people, and mentioned local businesses. Looking back, wow. I really did not have any deaf role models other than these peers."

The education system provides different opportunities to get support, whether from peers, teachers, or other professionals in the school system. The participants who stayed in the area did not make any mention of teachers when asked about support. The two participants who left mentioned that they "did not remember if teachers [in the area] encouraged them to go to college". However, once they left and enrolled in different schools, they were encouraged to go to Gallaudet University or the South West College of the Deaf.

The differences in VR services between the area and large cities led to different types of opportunities for the participants as well. In the group that left, Christopher was extremely vocal about the purpose of VR and what a counselor is responsible for in addition to ensuring that businesses are ADA compliant, stating that he "often seeks information online regarding laws to find a solution to the problem." He mentioned that VR services in the state's capital city provided quicker and more effective services when compared to VR services in the area. When asked about different barriers he had experienced, Christopher responded that he "mostly had accessibility barriers related to his physical disability. In some situations, I overcame the barriers and used that as an opportunity to educate others about disability rights." Elizabeth mentioned that her mother refused to allow her to receive SSI benefits, stating that she was required to go to college. However, her VR counselor at the time made it mandatory that she receive SSI before going to college with VR support.

In contrast, the participants who still remain in the area all reported that they did not have help from their VR counselor in their job searches. Alvin mentioned that the "office has closed. I do not have a counselor. I may need to try 
the state's Rehabilitation Commission next and see what happens." It should be noted that the acronyms Alvin used had been phased out more than five years prior, showing that he did not have access to updated information about services available to him in the area. Daniel and Fawn shared similar sentiments, saying that "the counselors were not friendly and supportive. They kept encouraging [Fawn] to choose other careers instead of the career I wanted.” The level of support that each participant received from different areas in their lives can also be seen in the education that each participant received.

\subsubsection{Education}

Both groups spent some time in the local school districts, leading to both similar as well as different experiences in education. Those who stayed in the local area had little to say about their educational experiences. In general, the school in the area resisted the use of ASL, preferring to use SEE. Bobby mentioned that prior to 5th grade, the teachers did not sign. Additionally, it was shared that the school district often contracted out to uncertified and unqualified interpreters who were not prepared for the different needs that come with education interpreting. When asked about their school experience, all of the participants mentioned that they had some classes in a self-contained Deaf Education classroom in the local school district. As one who left the area, Christopher pointed out;

The teachers had very low expectations. They did not challenge us to think critically. I could sense that they felt sorry for us. Their ultimate goal for us was to work in the post office rather than succeeding in life. One of my classmates actually told the teacher that he wanted to be a mechanic and was told that it would be "too hard" for him, and it would be best that he worked in the post office.

For those who left, their experiences at Deaf-centric educational centers provided them the mentoring to not only graduate from high school but to continue on into postsecondary programs. Both Christopher and Elizabeth had a member of their family who was in the service; therefore, they went to different schools across the country, including Deaf schools with the highest graduation rates as well as high entry rates into Gallaudet University in Washington, DC. These experiences provided deaf role models, both in the dorms during high school, and later peers in their postsecondary experiences. These individuals moved into a higher level of empowerment in their lives.

\subsubsection{Empowerment}

The interviews showed different levels of opportunities between participants, with the two who left the area showing that they had access to different types of opportunities, which led to success in life through this empowerment. For instance, in the group that stayed, Fawn mentioned that the availability of qualified interpreters in the area is limited, and "sometimes I have to take my husband to my work to interpret for me." When asked about ADA to see if each participant knew what it meant, quite striking was the fact that Bobby, who is in his mid 
50's, said he had "no clue what ADA means." Alvin responded that his understanding of the purpose of ADA was "if you file something [lawsuit] then it helps you". These varying levels of support and empowerment led to wide discrepancies in long term outcomes.

The local community includes several community colleges that prepare individuals for opportunities in technical fields. One individual who stayed, Alvin, has certifications in repairing diesel engines as well as more general auto body skills; regardless, he has not been able to get a job in his field. The types of jobs available for this group tends to be low paying, leaving the individuals earning less than they can on SSI. Given this situation, most of them gave up looking for jobs and remain on SSI. Bobby established a lawn service business with the help of his mother and this business with his SSI provides him a comfortable life. Alvin receives SSI benefits as well, stating that he had been out of work since August of 2019 due to discrimination. In contrast, those who left for additional schooling obtained professional jobs working in state schools for the deaf or teaching at the university level. Elizabeth taught deaf education for seven years, leaving to raise her own children. During that time she obtained a doctoral degree, which then allowed her to work at a university, a "setting that I never thought was in the picture as I never thought that I would try". Similarly, Christopher has worked in the field of deaf education in various roles, from a dorm supervisor at a state Deaf school to being a tutor at a community college. His last position was as a Student Service Coordinator at a state Deaf school, but due to COVID-19, he has become unemployed.

These opportunities either provided empowerment to become independent and self-sufficient or provided an external solution to the individual's problem, providing them immediate opportunities but not problem-solving skills that could empower them throughout their life. The level of empowerment each participant has also allowed or prevented them from moving into a Deaf identity.

\subsubsection{Identity}

The previously mentioned themes lead to the next code, identity. Again, the sense of identity differed between the two groups. It appears that the participants who left were able to develop a stronger sense of identity. Christopher stated that "when I lived there [in the area], I labeled myself as hard of hearing as I could speak well and wore hearing aids. When I left and went to the state Deaf school then Gallaudet University, my identity shifted, and I now label myself as capital D with a Deaf identity."

The emphasis on speaking well and wearing hearing aids can be seen in the participants who still reside in the area, with David responding that "I am hard of hearing, I can speak well" and Alvin echoing that sentiment, "I am hard of hearing and can hear with my right ear with a hearing aid." All the participants who stayed in the area wanted to emphasize two things: they have hearing aids and that they can speak well. Therefore, it seems that identity resulted from empowerment and having Deaf role models. This importance of this developmental 
process is access to aspirational capital and a feeling of "I can" as noted by Elizabeth who has achieved more than she originally dreamed.

\section{Discussion}

This project highlights factors that lead to more success for deaf individuals living in smaller communities that include the ability to communicate, having family and community support that in turn leads to empowering individuals to control their destiny in obtaining a quality education. Another factor found among those who left the area and achieved higher educational and professional goals was that of developing a Deaf identity. These findings parallel those of Wheeler-Scruggs (2003) who identified three categories of risk factors including personal attributes, social conditions, and service delivery.

These risk factors were expressed differently between those who stayed versus those who left the area. For those that stayed, the lack of effective early communication and language exposure point out issues with both the social conditions and service delivery provided in the area. Parents frequently do not understand the benefit of sign language for early cognitive and social emotional development. This issue leads to a lack of effective early communication and later social isolation and poor peer relationships. Calderon and Greenberg (2011) state that the key experiences for effective social and emotional development include effective and positive communication, strong social networks, emotional and motivational understanding of self and others, self-control and self-direction, empathy, peer friendships, and especially for deaf children the ability to cope with stereotyping and stigma (p. 188). The results here suggest that the ecology for these individuals did not include the support needed to develop into independent and socially effective, self-sufficient adults. Calderon and Greenberg emphasize the need for parents and professionals to work together to facilitate effective developmental outcomes for deaf children.

In contrast, those individuals who left the local community had a different cognitive ecology (Hutchins, 2010). Their parents found opportunities to provide early sign language and encouraged interactions at state schools for the deaf where they developed social skills and friendships with other deaf children. Parents here had higher expectations and told their deaf child that they would go to college. These parents found opportunities to work with professionals and programs that allowed them to have high expectations for their child as noted by Ingber and Dromi (2013). Such ideas were also reflected in our survey findings, with less than half of participants reporting they had completed a 4 year degree or higher. Additionally, these opportunities can be seen with only one/fifth of the survey participants in the local area reporting that they had been employed long-term. These early and effective interactions established a cognitive ecology that provided the support and opportunities for positive developmental outcomes that led to independent and self-sufficient adults.

These themes highlight the importance of Deaf cultural capital (Hamilton \& 
Clark, 2020) as well as the importance of having an identity with a supportive and empowering community (Garberoglio et al., 2020). Finding one's voice creates this empowerment and provides the capital to overcome "fear, denial, and passivity" (Garberoglio et al., 2020: p. 371). Here, those that stayed became trapped in the cycle of low expectations within families and schools, while those that left had more support to reach beyond the systematic oppression typically experienced by marginalized groups (Branson \& Miller, 2002). The explicit use of a deaf mentor is essential in areas with a weak deaf community. The amount of survey participants who reported having a mentor is equal to the amount of survey participants who reported gaining a higher education. Finding aspiration capital with Deaf role models and finding a sense of community seems vital to educational and vocational success.

To increase the postsecondary outcomes for Deaf individuals, it is necessary to provide systematic change to address reduced language accessibility at home, school, and in the workplace (Cawthon et al., 2016). The first theme addressed here, that of communication, separated those who experienced more success from those who were less successful as adults. The inability to effectively communicate, both at home and later, at school creates language delays that lead to increasing harm throughout the developmental trajectory (Humphries et al., 2012). To prevent these types of cascading negative events, Humphries et al. (2012) advocate for early sign language access. To provide this access, communities need to support families with deaf children and help to connect these families to deaf role models and the Deaf community (Garberoglio et al., 2020). Importantly, those families that signed in this study had children who grew into productive, successful adults.

For those who left the area, the use of sign language and/or sign communication in the family lead to access to deaf role models and aspirational capital (Listman et al., 2011). These experiences in turn lead to a Deaf identity and more positive psychological well-being (Chapman \& Dammeyer, 2017). Those who left the area noted struggles, but they demonstrated resilience that allowed them to overcome obstacles. They had both a Deaf community and a Deaf identity to sustain them (Cue, 2020). They obtained the Deaf community capital needed to navigate more effectively in a hearing culture (Cawthon et al., 2016; Hamilton \& Clark, 2020, Listman et al., 2011).

Regardless, cultural differences create stress in workplace environments related to the values noted in Table 1; Greene-Woods et al. (2021) found that many deaf adults are not aware of these differences, frequently related to Grice's maxims of politeness. Following Deaf culture and being blunt and direct is frequently interpreted as rude in deaf-hearing interactions; this issue was noted in participants' comments regarding reasons why they dropped out of the workforce. Cue (2020) found that many deaf individuals did not have a clear understanding of hearing culture; they simply labeled it "not Deaf culture" or the opposite of Deaf culture. Moreover, this lack of awareness of these cultural differences leads to difficulties, which are labeled differently by deaf (oppression) and 
hearing (rude) individuals.

However, those who left the area developed resilience, which is helpful at the individual level, but does not impact the systematic oppression that affects marginalized deaf communities (Garberoglio et al., 2020). Participants with other intersectional identities reported additional struggles in their lives, such as being Black and Deaf (Myers et al., 2010) or Deaf with additional disabilities (Musyoka et al., 2017). As noted by Garberoglio et al. (2020) there is a need to create ecologies that can recognize skills and strengthen resources for these individuals who have multiple identities that lead to severe oppression. Garberoglio's team from the National Deaf Center encourages the use of eight strategies to create strong deaf communities, including: identifying and engaging in system change solutions, improving partnerships and resource sharing, strengthening the transition process from school to work, building communities of support for deaf youth, supporting families, improving access to programs and services, and providing professional development (Garberoglio et al., 2020; Engage for Change/National Deaf Center).

It appears that those who left the area in this study and went to larger cities were able to access the type resources needed for success, which was found in places with already established strong deaf communities. These communities allowed the participants the opportunity to build their network, have access to mentorship, and be encouraged to attend college and obtain employment in their field of choice. Additionally, due to the strong deaf communities in these cities, the VR services were more effective and knowledgeable about how to best serve deaf clients. Having access to a deaf-centric ecological system appears to be what benefits deaf adults in their personal and professional lives. Those who stayed in this mid-sized rural area continued to stay in the cycle of low expectations placed upon them by the educational system.

\section{Conclusion}

In conclusion, this research suggests that effective collaborations between families, service providers, educational programs and the local deaf community provides the network needed to support deaf infants growing into successful deaf adults. Early outreach to parents to help reduce the stigma frequently associated with being deaf can provide support for early access to sign language, which is known to lead to more effective outcomes (Humphries et al., 2012). In these ways, an integrated "village" or community can increase educational opportunities, provide mentors, increase social emotional development and accept deaf community members for more effective outcomes for most if not all members of the community.

\section{Limitations and Recommendations for Future Research}

There are several limitations in this study. Our findings provide a snapshot at the lives of deaf individuals in a mid-sized city, but it cannot be assumed to be a 
complete description; therefore, these findings cannot be generalized. There are many additional variables that must be considered, such as the age range of the population, types of educational programs, the availability of interpreting services, population demographics, and family backgrounds. Another limitation in this study is the small sample size, and the identity of our participants. The majority of our participants reported a White identity, with only one reporting that he identified as Black and another as mixed race. Additionally, all but one of our participants were able-bodied. A larger sample size with a more diverse population is needed to determine the influences of multiple identities on participants' experiences in their communities.

Future research should replicate this study with a larger sample size that represents a more diverse population. Additional research should be conducted with participants who grew up in larger cities with strong deaf communities to determine the differences between those who grew up in areas with weak deaf communities. Future research should also focus on the eight strategies as listed by Garberoglio et al., (2020) and strive to embed these strategies in the communities. It is clear that systematic change must happen, from the quality of interpreters to the expectations of teachers in the field. It is clear that partnership and resource sharing must happen between various agencies to best benefit deaf communities. Such partnerships should also include transition planning for deaf students in high school that defy the cycle of low expectations. Additional research is needed on what families and youth in mid-sized cities need in terms of resources, support, and opportunities in order to build a stronger community of support for deaf children. It is hoped that this and future research will lead to the ability for all towns to build the "village" where deaf individuals can become part of a successful ecology.

\section{Conflicts of Interest}

The authors declare no conflicts of interest regarding the publication of this paper.

\section{References}

ADA (1990). Americans with Disabilities Act of 1990, 42 U.S.C. $\$ 12101$ et seq. https://www.ada.gov/pubs/adastatute08.htm

Branson, J., \& Miller, D. (2002). Damned for Their Difference: The Cultural Construction of Deaf People as "Disabled": A Sociological History. Washington DC: Gallaudet University Press.

Calderon, R., \& Greenberg, M. (2011). Social and Emotional Development of Deaf Children: Family, School, and Program Effects. In The Oxford Handbook of Deaf Studies, Language, and Education (Vol. 1, pp. 188-199). Oxford: Oxford University Press. https://doi.org/10.1093/oxfordhb/9780199750986.013.0014

Cawthon, S. W., Johnson, P. M., Garberoglio, C. L., \& Schoffstall, S. J. (2016). Role Models as Facilitators of Social Capital for Deaf Individuals: A Research Synthesis. American Annals of the Deaf, 161, 115-127. https://doi.org/10.1353/aad.2016.0021

Chapman, M., \& Dammeyer, J. (2017). The Significance of Deaf Identity for Psychologi- 
cal Well-Being. The Journal of Deaf Studies and Deaf Education, 22, 187-194. https://doi.org/10.1093/deafed/enw073

Cue, K. R. (2020). Hegemonic Deaf and Hearing Cultures in the United States: A Deaf Ecological Systems Perspective. Doctoral Dissertation, Beaumont, TX: Lamar University.

Dammeyer, J., Crowe, K., Marschark, M., \& Rosica, M. (2019). Work and Employment Characteristics of Deaf and Hard-of-Hearing Adults. The Journal of Deaf Studies and Deaf Education, 24, 386-395. https://doi.org/10.1093/deafed/enz018

Easterbrooks, S. R., \& Beal-Alvarez, J. S. (2012). States' Reading Outcomes of Students Who Are d/Deaf and Hard of Hearing. American Annals of the Deaf, 157, 27-40. https://doi.org/10.1353/aad.2012.1611

Eraser, D. M., Hansmann, S., \& Saladin, S. P. (2019). Psychosocial Aspects of Deafness: Implications for Rehabilitation Counselors. JADARA, 43, 52-68. https://repository.wcsu.edu/jadara/vol43/iss1/6

Garberoglio, C. L., Guerra, D. H., Sanders, G. T., \& Cawthon, S. W. (2020). Community-Driven Strategies for Improving Postsecondary Outcomes of Deaf People. American Annals of the Deaf, 165, 369-392. https://doi.org/10.1353/aad.2020.0024

Greene-Woods, A., Delgado, N. J., Buchanan, B., Sides, M., Behmanesh, A. A., Cheslik, B., Koo, C. K., \& Clark, M. D. (2021). Deaf Cultural Capital and Its Conflicts with Hearing Culture: Navigational Successes and Failures. JADARA, 54, 15-30. https://repository.wcsu.edu/jadara/vol54/iss1/2

Hamilton, B., \& Clark, M. D. M. (2020). The Deaf Mentor Program: Benefits to Families. Psychology, 11, 713-736. https://doi.org/10.4236/psych.2020.115049

Humphries, T., Kushalnagar, P., Mathur, G., Napoli, D. J., Padden, C., Rathmann, C., \& Smith, S. R. (2012). Language Acquisition for Deaf Children: Reducing the Harms of Zero Tolerance to the Use of Alternative Approaches. Harm Reduction Journal, 9, 16. https://doi.org/10.1186/1477-7517-9-16

Humphries, T., Kushalnagar, P., Mathur, G., Napoli, D. J., Padden, C., Rathmann, C., \& Smith, S. (2016). Avoiding Linguistic Neglect of Deaf Children. Social Service Review, 90, 589-619. https://doi.org/10.1086/689543

Hutchins, E. (2010). Cognitive Ecology. Topics in Cognitive Science, 2, 705-715. https://doi.org/10.1111/j.1756-8765.2010.01089.x

Ingber, S., \& Dromi, E. (2013). Demographics Affecting Parental Expectations for Early Deaf Intervention. Deafness and Education International, 11, 83-111. https://doi.org/10.1179/146431509790559624

Kelley, K., Clark, B., Brown, V., \& Sitzia, J. (2003). Good Practice in the Conduct and Reporting of Survey Research. International Journal for Quality in Health Care, 15, 261-266. https://doi.org/10.1093/intqhc/mzg031

Listman, J., Rogers, K. D., \& Hauser, P. C. (2011). Community Cultural Wealth and Deaf Adolescents' Resilience. In D. H. Zand, \& K. J. Pierce (Eds.), Resilience in Deaf Children (pp. 279-297). Berlin: Springer Nature. https://doi.org/10.1007/978-1-4419-7796-0 11

Mitchell, R. E., \& Karchmer, M. (2004). Chasing the Mythical Ten Percent: Parental Hearing Status of Deaf and Hard of Hearing Students in the United States. Sign Language Studies, 4, 138-163. https://doi.org/10.1353/sls.2004.0005

Mukari, S. Z., Ling, L. N., \& Ghani, H. A. (2007). Educational Performance of Pediatric Cochlear Implant Recipients in Mainstream Classes. International Journal of Pediatric Otorhinolaryngology, 71, 231-240. https://doi.org/10.1016/j.ijporl.2006.10.005 
Musyoka, M. M., Gentry, M. A., \& Meek, D. R. (2017). Perceptions of Teachers' Preparedness to Teach Deaf and Hard of Hearing Students with Additional Disabilities: A Qualitative Case Study. Journal of Developmental and Physical Disabilities, 29, 827-848. https://doi.org/10.1007/s10882-017-9555-Z

Myers, C., Clark, M. D., Musyoka, M. M., Anderson, M. L., Gilbert, G. L., Agyen, S., \& Hauser, P. C. (2010). Black Deaf Individuals' Reading Skills: Influence of ASL, Culture, Family Characteristics, Reading Experience, and Education. American Annals of the Deaf, 155, 449-457. https://doi.org/10.1353/aad.2010.0044

Naderifar, M., Goli, H., \& Ghaljaie, F. (2017). Snowball Sampling: A Purposeful Method of Sampling in Qualitative Research. Strides in Development of Medical Education, 14, e67670. https://doi.org/10.5812/sdme.67670

Punch, R. (2016). Employment and Adults Who Are Deaf or Hard of Hearing: Current Status and Experiences of Barriers, Accommodations, and Stress in the Workplace. American Annals of the Deaf, 161, 384-397. https://doi.org/10.1353/aad.2016.0028

Stokar, H., \& Orwat, J. (2018). Hearing Managers of Deaf Workers: A Phenomenological Investigation in the Restaurant Industry. American Annals of the Deaf, 163, 13-34. https://doi.org/10.1353/aad.2018.0009

Surian, L., Tedoldi, M., \& Siegal, M. (2010). Sensitivity to Conversational Maxims in Deaf and Hearing Children. Journal of Child Language, 37, 929. https://doi.org/10.1017/S0305000909990043

Wheeler-Scruggs, K. (2003). Discerning Characteristics and Risk Factors of People Who are Deaf and Low Functioning. Journal of Rehabilitation, 69, 395-414. 